G.T. Hemmings MD FRCPC,

D.G. Whalley MB FFARCS FRCPC,

P.J. O'Connor MD FRCPC, A. Benjamin MD FRCS FACs,

C. Dunn RN

\title{
Invasive monitoring and anaesthetic man- agement of a parturient with mitral stenosis
}

The anaesthetic management of a parturient with mitral stenosis is presented and discussed. In particular, the beneficial effects of epidural artaesthesia for vaginal delivery are described with respect to the significant improvement noted in haemodynamic parameters. The information derived from the pulmonary artery catheter greatly assisted the management of the patient throughout labour and in the puerperium.

Rheumatic heart discasc has become a rare occurrence in women of childbearing age, yet mitral stenosis is still the most frequent valvular lesion seen in this group of patients.' The increase in blood volume that occurs in pregnancy causes pulmonary artery pressure to rise in these patients, ${ }^{2}$ which may result in pulmonary congestion, dilatation of the left atrium and atrial fibrillation. In the normal patient, labour is associated with an increase in cardiac output, heart rate and stroke volume. ${ }^{3}$ Such changes are thought to be sympathetically mediated and are likely due to the combined effects of pain, increased metabolic demands and increased venous return during uterine contraction. Patients with mitral stenosis are at an increased risk of decompensating during this period as the additional demands made on the heart may not be well tolerated.

Recently, Clark et al. reported the results of invasive haemodynamic monitoring in a series of eight patients with mitral stenosis. ${ }^{4}$ It is the first clinical report of this nature. Three of these patients received epidural anaesthesia during the active phase of labour, without any significant improvement in haemodynamic parameters.

\section{Key words}

EQUIPMENT: pulmonary artery catheter; HEART: mitral valve stenosis; PREGNANCY.

From the Departments of Anaesthesia, and Obstetrics and Gynaecology, McGill University, Royal Victoria Hospital, Montreal, Quehec.

Address correspondence to: Dr. G.T. Hemmings, Department of Anaesthesia, Royal Victoria Hospital, 687 Pine Avenue West, Montreal, Quebec, H3A 1 A1.
In contrast, this report describes the results of haemodynamic monitoring in a parturient with mitral stenosis in whom epidural anaesthesia had beneficial effects.

\section{Case report}

A 33-year-old primigravida known to have mitral stenosis was admitted for bed rest at 37 weeks of gestation. She had undergone a mitral commisurotomy 10 years previously and had been asymptomatic until the third trimester of pregnancy. At 33 weeks of gestation she had begun to receive furosemide $20 \mathrm{mg} P O$ daily because of dyspnoea on exertion after walking six blocks, orthopnoea, and frequent paroxysmal noctumal dyspnoea. She had not responded satisfactorily and had therefore been admitted for bedrest.

At the time of admission, physical examination revealed a $77 \mathrm{~kg}$ woman with a systemic blood pressure of $130 / 60$ $\mathrm{mmHg}$ and a regular heart rate of 70 beats $/ \mathrm{min}$. Jugular venous distention was noted and a right ventricular lift was evident on palpation. A grade II/VI apical diastolic murmur was heard as well as a grade II/VI pansystolic murmur at the left sternal border and radiating toward the axilla. The first heart sound was prominent and an opening snap was heard at the apex. The lungs were clear to auscultation. Arterial blood gas analysis was within normal limits. No abnormality was evident on the electrocardiogram but an echocardiogram done at 33 weeks of gestation showed a thickened and calcified mitral valve with an immobile posterior leaflet. The left atrium was moderately dilated with delayed emptying of the left atrium suggestive of mild nitral stenosis but with no evidence of regurgitation.

At 38 weeks of gestation the patient was prescribed propanolol $10 \mathrm{mg}$ q.i.d., after cardiological consultation. Induction of labour was planned for the 39th week of gestation but this had to be delayed one week due to an unfavourable cervix. Prostaglandins were not used to ripen the cervix because of the possible effects on the pulmonary vasculature and on bronchial smooth muscle.

On the morning of induction, a modified $v_{5}$ matemal ECG was applied, an arterial cannula was inserted in the left radial artery and an Oxymetrix P71 10 Opticath ther. 
TABLE Haemodynamic measurements and derived indices during labour and the puerperium

\begin{tabular}{|c|c|c|c|c|c|c|c|c|}
\hline & \multirow[b]{2}{*}{$\begin{array}{l}\text { Prior to } \\
\text { induction } \\
\text { of labour }\end{array}$} & \multicolumn{2}{|c|}{ First stage of labotir } & \multicolumn{3}{|c|}{ Second siage of labour } & \multicolumn{2}{|c|}{ Postpartum } \\
\hline & & $\begin{array}{l}\text { During } \\
\text { painful } \\
\text { contractions }\end{array}$ & $\begin{array}{l}\text { After } \\
\text { bupivacaine } \\
0.25 \% \text { plain } \\
12 \mathrm{ml}\end{array}$ & $\begin{array}{l}\text { During } \\
\text { contractions } \\
\text { with bearing } \\
\text { down }\end{array}$ & $\begin{array}{l}\text { Berween } \\
\text { contractions }\end{array}$ & $\begin{array}{l}\text { After } \\
\text { lidocaine } \\
2 \% \text { piain } \\
8 \mathrm{ml}\end{array}$ & $10 \mathrm{~min}$ & $12 \mathrm{hr}$ \\
\hline $\begin{array}{l}\text { Systemic arterial pressure } \\
\text { (mm Hg) }\end{array}$ & $110 / 58$ & $128 / 65$ & $125 / 54$ & $148 / 105$ & $135 / 87$ & 137187 & $139 / 75$ & $115 / 65$ \\
\hline Hcart rate (beats/min ${ }^{-1}$ ) & 72 & 67 & 58 & 83 & 78 & 85 & 78 & 70 \\
\hline $\begin{array}{l}\text { Pulmonary artery pressure } \\
\qquad(\mathrm{mmHg})\end{array}$ & $37 / 12$ & $65 / 23$ & $43 / 15$ & - & $45 / 15$ & $45 / 18$ & $38 / 14$ & - \\
\hline $\begin{array}{l}\text { Mean pulmonary artery pressur } \\
(\mathrm{mmHg})\end{array}$ & 20.3 & 36 & 21.6 & 46 & 25 & 27 & 21 & - \\
\hline $\begin{array}{l}\text { Pulmonary capillary wedge } \\
\text { pressure ( } \mathrm{mmHg})\end{array}$ & 18 & 23 & 14 & 31 & 14 & 18 & 13 & 14 \\
\hline $\begin{array}{l}\text { Central venous pressure } \\
\qquad(\mathrm{mmHg})\end{array}$ & 2 & 10 & 9 & 23 & 3 & 3 & 3 & 0 \\
\hline Cardias output $\left(\mathrm{L} \cdot \mathrm{min}^{-1}\right)$ & 6.5 & 4.92 & 5.96 & 4.1 & 5.6 & 6.5 & 6.2 & 5.38 \\
\hline $\begin{array}{l}\text { Systemic vascular resistance } \\
\left(\text { dyne } \cdot \sec \cdot \mathrm{cm}^{-5}\right)\end{array}$ & 934 & 1224 & 920.8 & 1619 & 1338 & 996 & 941 & 1189 \\
\hline $\begin{array}{l}\text { Pulmonary vascular resistance } \\
\text { (dyne } \sec \cdot \mathrm{cm}^{-5} \text { ) }\end{array}$ & 24.6 & 211 & 88 & 292 & 157 & 110 & 103 & - \\
\hline $\begin{array}{l}\text { \% mixed venous oxygen } \\
\text { saturation }\end{array}$ & 73 & 73 & 65 & 72 & 72 & 80 & 76 & - \\
\hline
\end{tabular}

modilution pulmonary artery catheter was inserted through the left antecubital fossa. An epidural catheter was inserted at the $\mathbf{L}_{2-3}$ interspace, without administration of local anaesthetic in the epidural space. Induction of labour was then started with an infusion of oxytocin, while the fetal heart rate was monitored continuously by external tococardiography and uterine contractions by an external monitor. The mixed venous oxygen saturation $\left(\mathrm{S}^{\mathrm{v}} \mathrm{O}_{2}\right)$ was monitored continuously and cardiac output (CO) was measured by the thermodilution technique at various times during labour and delivery. The reported values for $\mathrm{CO}$ were obtained by calculating the mean of three measurements. The lateral position was maintained throughout the first stage of labour. During the second stage of labour, left uterine displacement was ensured by a wedge shaped cushion under the right hip. All measurements were obtained in the lateral or semi-lateral position between contractions, except where specifically stated. Haemodynamic measurements and derived indices obtained throughout labour are shown in the Table.

When the contractions became painful, $C O$ decreased and the pulmonary capillary wedge pressure (PCWP) increased. Measurements obtained between the contractions are not reported in the table but were essentially similar. After pain was relieved by epidural analgesia, $\mathrm{CO}$ and PCWP returned toward baseline. Bearing down during the second stage of labour resulted in a marked increase in pulmonary artery pressure (PAP) and PCWP and in the appearance of a " $v$ " wave on the PCWP tracing. The patient was subsequently instructed not to bear down and was placed in a semirecumbant position. The fetal head was allowed to descend without expulsive efforts until low forceps could be applied to assist delivery. $\mathrm{CO}$ and PAP did not increase at any time during the puerperium.

Heart rate (HR) was well controlled throughout labour and the puerperium, reaching a maximum of 85 beats/min during the second stage of labour, and sinus thythm was maintained. Propanolol administration was continued orally during labour and the postpartum period.

The patient received $1100 \mathrm{ml}$ of intravenous fluids during the $12 \mathrm{hr}$ before delivery and $1035 \mathrm{ml}$ during the $12 \mathrm{hr}$ following delivery. Urine output was $900 \mathrm{ml}$ over $24 \mathrm{hr}$ and the blood loss at delivery was estimated to be $500 \mathrm{ml}$.

The total dose of bupivacaine and lidocaine used during labour were $130 \mathrm{mg}$ and $160 \mathrm{mg}$ respectively. Antibiotic prophylaxis was provided with netilmicin $100 \mathrm{mg}$ IV and penicillin 1 million units IV during labour and three additional doses of each were given during the following $36 \mathrm{hr}$.

A $3390 \mathrm{~g}$ female infant was delivered with Apgar scores of 6 at $1 \mathrm{~min}$ and 9 at $5 \mathrm{~min}$. The umbilical venous $\mathrm{pH}$ was 7.35 and at no time was hypoglycaemia or bradycardia observed in the newborn.

Full invasive hacmodynamic monitoring of the patient 
was continued ovemight in the Recovery Room. No significant changes in any of the haemodynamic parameters were noted and her recovery was uneventful.

\section{Discussion}

During pregnancy, blood volume increases by an average of 40 per cent above non-pregnant levels. ${ }^{5} \mathrm{CO}$ begins to increase during the first trimester and by $28-32$ weeks it has increased by up to 40 per cent above non-pregnant Jevels. This increase in $\mathrm{CO}$ is due to an increase in both stroke volume (SV) and HR, but as term approaches, $\mathrm{CO}$ and SV decrease somewhat and HR increases. ${ }^{6}$ Normally there is no increase in pulmonary artery pressure in the pregnant patient, despite the increase in blood volume.?

In the patient with mitral stenosis, pregnancy is also associated with an increase in CO. There is also an increase in PAP, which is probably due to the increase in blood volume. ${ }^{2}$ If there is preexistent pulmonary hypertension, this increase in PAP may lead to pulmonary congestion and it may be necessary to initiate diuretic therapy during pregnancy if pulmonary congestion occurs.

Tachycardia is not well tolerated by patients with mitral stenosis as it will decrease the time available for filling of the left ventricle during diastole. Dilatation of the left atrium as a result of an increase in central blood volume may lead to atrial fibrillation which will further impair left ventricular filling. Digoxin is often given prophylactically during pregnancy to patients with mitral stenosis to prevent tachycardia and atrial fibrillation. Beta adrenergic antagonists may also be used for this purpose as left ventricular dysfunction is not usually present.

Labour and delivery impose additional stresses on the cardiovascular system. In the normal patient, there is a progressive increase in $\mathrm{CO}$ during the peripartal period which is accompanied by an increase in both $\mathrm{HR}$ and $\mathrm{SV}^{3}$ This increase in $\mathrm{CO}$ is thought to result from increased sympathetic stimulation sccondary to pain and increased metabolic demand. Uterine contractions cause a further $15-20$ per cent increase in $\mathrm{CO},{ }^{8}$ probably as a result of blood being transfused from the uterus into the central veins as well as increased sympathetic stimulation due to pain. $\mathrm{CO}$ is increased by 30 per cent when the pregnant patient at term is turned from the supine to the lateral position ${ }^{9}$ by relieving aortocaval compression and it is therefore recommended that the parturient should labour in the lateral position. $\mathrm{CO}$ and HR are maximal during the immediate post partum period at which time $\mathrm{CO}$ is approximately 80 per cent above non-pregnant levels. ${ }^{3}$ The most likely causes are an increase in venous return as a result of the disappearance of aortocaval compression, as well as an autotransfusion of blood to the central veins by the contracted uterus. This increase in intravascular volume and heart rate makes the patient with mitral stenosis particularly vulnerable to the development of pulmonary uedema at this time.

Epidural anaesthesia for labour usually results in a sympathetic block from approximately $\mathrm{T}_{\text {to }}$ downward. $\mathrm{CO}$ and uterine blood flow (UBF) must be maintained by slow induction of the epidural block and maintaining the lateral position. In addition, at least $500 \mathrm{ml}$ of intravenous fluid is administered to increase preload. Epidural anaesthesia has been shown to decrease catecholamine levels in the parturient ${ }^{10}$ and to attenuate the increase in cardiac output seen in the parturient. ${ }^{3}$ These beneficial cffects of epidural anaesthesia are especially relevant in the patient with mitral stenosis, particularly during the puerperium. Consequently, we consider that it is important to continue close haemodynamic monitoring during this period and to administer epidural local anaesthetic should an increase in PCWP be evident. This was not necessary in our patient as pulmonary artery pressure did not rise in the puerperium

According to the guidelines of the American Heart Association, antibiotic prophylaxis is not necessary for vaginal delivery in patients with valvular heart disease." Most physicians do however administer prophylactic antjbiotics to such patients as the risk/benefit ratio is low.

Clark et $a l .^{4}$ recently published the first report on invasive haemodynamic monitoring in a series of eight patients with mitral stenosis, four of whom had mitral regurgitation and/or other valvular lesions. They did not observe the increase in $\mathrm{CO}$ that is normally seen in the parturient but they did observe an increase in the PCWP of approximately $10 \mathrm{mmHg}$ in the postpartum period. They concluded that the patient with mitral stenosis has a limited ability to increase her $\mathrm{CO}$ during labour and that this results in increased filling pressures when the venous return to the heart is increased during the third stage of labour. There was no correlation between CVP and PCWP in the patients in that series, neither were there any important haemodynamic changes in the three patients who received epidural anaesthesia.

The observations in our patient differ from those described above in several respects. Firstly, wc found epidural anaesthesia to be very bencficial to our patient during the first stage of labour. When contractions became painful, before the induction of epidural anaesthesia, PAP, pulmonary vascular resistance (PVR) and systemic vascular resistance ( $S V R$ ) increased, while $C O$ decreased. Similar values were obtained between contractions and cannot be attributed to the performance of a valsalva manoeuvre. The induction of epidural anaesthesia caused PVR and SVR, as well as PAP, to decrease while CO increased toward baseline values. This was maintained throughout the first stage of labour (Table). 
Secondly, we observed dramatic increases in PAP as well as a decrease in $\mathrm{CO}$, during bearing down efforts in the second stage of labour (Table). This was associated with the appearance of a " $v$ " wave on the PCWP tracing which was not present beforehand, indicating that this patient may not have had pure mitral stenosis, as the echocardiogram had lead us to believe, but possibly a degree of mitral regurgitation which increased during the bearing down efforts. Valsalva-like manoeuvres cause an increase in SVR which may increase mitral regurgitation and this probably contributed to the decrease in $\mathrm{CO}$ in our patient. Other factors which may explain the decrease in $\mathrm{CO}$ that we observed in the patient during bearing down are the decreased venous return that results from an increase in intrathoracic pressure and increase in pulmonary vascular resistance. The PAP obtained during a valsalva manoeuvre does not represent left atrial transmural pressure because the airway pressure also increases. Consequentiy, the derived values such as PVR and SVR cannot be calculated on the basis of the observed PAP and PCWP alone. It would seem wise to avoid maternal expulsive efforts during the second stage and to allow the presenting part to descend by the force of uterine contractions alone, aided by gravity, and to facilitate delivery by the use of forceps as soon as it is safe to do so. This is easier to accomplish with epidural anaesthesia as the patient's urge to bear down is decreased.

Thirdly, we did not observe an increase in PCWP in the immediate postpartum period. This is probably due to several factors, including conservative fluid management during labour, blood loss at delivery, and a sympathetic blockade to $\mathrm{T}_{6}$ (Table).

Fourthly, Clark et al. did not report their observations for HR in their patients. The increase in HR that would be expected in the parturient was not seen in our patient and this was most probably due to effective beta adrenergic blockade. If control of the heart rate cannot be achieved with oral propanolol, intravenous administration of this drug may be necessary. Epidural anaesthesia may have contributed to the successful control of HR during labour as it prevents increases in sympathetic activity secondary to pain. ${ }^{3}$

This case report, as well as the series reported on by Clark et al., illustrates the necessity of measuring the PAP in parturients with clinically significant mitral stenosis, since the PCWP cannot be predicted from the CVP. Wc found the information provided by the pulmonary artery catheter invaluable in guiding our fluid manage. ment during the induction and maintenance of epidural anaesthesia and throughout the conduct of labour.

\section{References}

I Szekely $P$, Turner $R$, Snaith $L$. Pregnancy and the changing pattern of rheumatic heart disease. Br Heart J 1973; 35 : 1293.

2 Sugishita Y, Llo I, Ozeki K, Ohia C, Kubo T. Intracardiac pressures in pregnant patients with mitral stenosis. Jpn Heart J 1981; 22: 885 .

3 Ueland K. Hansen JM. Maternal Cardiovascular Dynamics III. Labour and delivery under local and caudal anesthesia Obstet Gynecol 1969; 103: 8.

4 Clark SL, Phelan JP, Greenspoon J, Aldahl D, Horenstein J. Labor and delivery in the presence of mitral stenosis: central hemodynamic observations. Am J Obstet Gynecol $1985 ; 152: 984$.

5 Pritchard JA. Changes in the blood volume during pregnancy and delivery. Anesthesialogy 1965; 26: 393.

6 Ueland K, Novy MJ, Peterson EN, MetcalfJ. Matemal Cardiovascular Dynamics IV. The influence of gestational age on the maternal cardiovascular response to posture and exercise. Am J Obstet Gynecol 1969; 104: 856.

7 Rose DJ, Bader ME, Bader RA, Braumwald E. Catheterization studies of cardiac hemodynamics in nomal pregnant women with reference to left ventricular work. Am J Obstet Gynecol 1956; 72: 233.

8 Uelund K, Hansen J. Matenal Cardiovascular Dynamies II. Posture and uterine contractions. Am J Obstet Gynecol $1969 ; 103: 1$

9 Ueland K, Gills $R$, Hansen JM. Matemal Cardiovascular Dynamics I. Cesarean section under subarachnoid block anesthesia, Am J Obstet Gynecol 1968; 100: 42.

10 Shnider SM, Abboud T, Artal R, Henriksen E, Stefani SJ $L e v i n s o n G$. Maternal catecholamines decrcasc during labor after lumbar cpidural ancsthesia. Am J Obstet Gynecol 1983; 147: 13.

11 Committce on Prevention of Rheumatic Fever and Bacterial Endocarditis of the American Heart Association. Prevention of bacterial endocarditis. Circulation 1977; 56: 139A.

Résumé

La conduite anesthésique d'une parturiente atteinte de sténose mitrale est présentée el discutée. En particulier on discute des effets benéfiques de l'analgésie épidurale lors de l'accouchement naturel surtout en ce qui concerne l'amélioration des paramètres hémodynamiques. Linformation recueillie par le cathéler de l'artère pulmonaire a contribué énormément à la condwite anesthésique chez cette patiente du travers le travail et le puerperium 